carefully inspected, very low. In the present paper: (1) it is shown that, even if overregularisations are a genuine grammatical alternative, overall rates in samples would still be low for most children; (2) careful analysis shows evidence for substantial overregularisation periods in three longitudinal participants ages $2 ; 5-5 ; 2$ (Abe), 2; 3-5; 2 (Adam) and 2; 3-5;0 (Samh); and (3) Abe's much higher rates follow from general developments in his past tense acquisition, in ways not consonant with Marcus et al.'s formulations.

00-686 Rowland, Caroline F. (U. of Derby, UK; Email: c.rowland@derby.ac.ukl and Pine, Julian M. Subject-auxiliary inversion errors and wh-question acquisition: 'what children do know?' Journal of Child Language (Cambridge, UK), 27, 1 (2000), 157-81.

This paper reports an analysis of correct wh-question production and subject-auxiliary inversion errors in one child's early wh-question data (age 2; 3.4 to 4 ; 10.23). It is argued that two current movement rule accounts cannot explain the patterning of early whquestions. However, the data can be explained in terms of the child's knowledge of particular lexically-specific wh-word + auxiliary combinations, and the pattern of inversion and uninversion predicted from the relative frequencies of these combinations in the mother's speech. The results are taken to support the claim that correctly inverted wh-questions can be produced without access to a subject-auxiliary inversion rule and are consistent with the constructivist claim that a distributional learning mechanism that learns and reproduces lexically-specific formulae heard in the input can explain much of the early multi-word speech data. The implications of these results for movement rule-based and constructivist theories of grammatical development are discussed.

\section{Bilingual education/bilingualism}

\author{
00-687 Carlisle, Joanne F., Beeman, Margaret, \\ Davis, Lyle Hull and Spharim, Galila \\ (Northwestern U., Evanston, IL, USA). Relationship \\ of metalinguistic capabilities and reading \\ achievement for children who are becoming \\ bilingual. Applied Psycholinguistics (Cambridge, \\ UK), 20, 4 (1999), 459-78.
}

The study reported here investigated the developing metalinguistic capabilities of Hispanic primary school children who are becoming bilingual but whose English reading achievement is below average. Tivo questioins were posed: first, whether native- (L1) and second-language (L.2) vocabulary and degree of bilingualism contribute to performance on a metalinguistic task (defining words); and, second, whether L1 and L2 vocabulary and metalinguistic development at the word level significantly predict reading comprehension in the spring. The results showed that performance on the definition task in English and in Spanish was significantly explained by word knowledge in the language of the task; performance on the definition task in the other language (English or Spanish) but not degree of bilingualism contributed significantly, after the effects of vocabulary in the two languages were accounted for. Both $\mathrm{L} 1$ and $\mathrm{L} 2$ vocabulary and phonological awareness independently contributed to achievement in English reading comprehension. The results suggest that, for children with limited L1 development in the early stages of bilingualism, vocabulary development in both the native and second language and metalinguistic development at the word level may be important education priorities because of their effects on $\mathrm{L} 2$ reading comprehension.

\section{0-688 Cathomas, Rico. Zur Wirksamkeit des} immersiven Unterrichts and den

bündnerromanischen Schulen in der Schweiz: eine empirische Untersuchung. IOn the effectiveness of immersion teaching in Rhaeto-Romance schools in the Grisons (Graubünden) in Switzerland: an empirical study.l Bulletin suisse de linguistique appliquée (Neuchâtel, Switzerland), 69, 2 (1999), 43-54.

In the Grisons in Switzerland there are bilingual schools (Rhaeto-Romance and German) which teach German using the immersion method. The author argues that such schools are an effective model for the preservation of the minority language as well as the optimal promotion of the majority language German. The data were taken from schools in Surselva that use Rhaeto-Romance as the language of instruction; students from German-language schools in the Grisons were used as control groups to examine the level of German competency. The empirical part of the study took place from 1993-1998 covering approximately 1300 students (from 6th to 9th class) and involved the following variables: school type/school model, school year/class, and questionnaire concerning mother tongue, language contact, attitudes and motivation. The dependent variable consisted of two standardised language tests. As this study forms part of a larger ongoing project, the results presented are only interim results but the author is of the opinion that the school model 'Rhaeto-Romance as language of instruction' is an ideal language preservation and immersion model that could be applied to other areas/regions.

\section{0-689 Cho, Grace (Biola U., CA, USA) and}

Krashen, Stephen. The role of voluntary factors in heritage language development: how speakers can develop the heritage language on their own. ITL Review of Applied Linguistics (Leuven, Belgium), 127-128 (2000), 127-40.

This article first outlines the advantages to heritage language (HL) development, including evidence of more school and occupational success, better communication with family and community members, and the promo- 
tion of a healthy sense of multiculturalism. But HLs are hard to maintain: language shift is powerful. The study reported here examines some of the factors that may play a role in HL development. First, the results of previous research on HL competence are reviewed. The present study involved 114 Korean Americans aged 18 to 30 (all except two): data were obtained via questionnaire (from the 98 participants enrolled in Korean language classes) and, from the remaining participants, through in-depth interviews. Results show that neither participants' age, length of residence nor duration of attending HL classes were significant predictors of $\mathrm{HL}$ competence.Visits to the country of origin and parental input, while remaining significant predictors, are factors which may be beyond the participants' voluntary control.The other significant predictors, however, i.e., reading and watching television in Korean, are within their control, and suggest that HL speakers can improve their knowledge of the HL on their own, even without contact with other HL speakers. The results are consistent with previous findings, and are seen as suggesting a painless (even pleasant) path that HL speakers can follow to improve their HL ability and reap the benefits of increased HL competence.

00-690 Crutchley, Alison (U. of Manchester, UK; Email: alison.crutchley@man.ac.uk).Bilingual children with SLI attending language units: getting the bigger picture. Child Language Teaching and Therapy (London, UK), 15, 3 (1999), 201-17.

Bilingual children with speech and language difficulties are an under-researched group. The present paper sets out to map out the field and to contextualise findings from four years of research into a group of bilingual children attending primary age language units across England. Differences between the bilingual group and their monolingual peers are summarised, and underlying themes and issues in the research are explored. These include the identification and assessment of bilingual children with specific language impairments (SLI), parental involvement in the educational process, knowledge, attitudes and awareness of teaching staff and availability of provision in schools for bilingual children.

\section{0-691 Crutchley, Alison (U. of Manchester,} UK); Email: alison.crutchley@man.ac.uk). Bilingual children in language units: does having 'wellinformed' parents make a difference? International Journal of Language and Communication Disorders (London, UK), 35, 1 (2000), 65-81.

Findings from a large-cohort study of children with speech and language impairments in language units attached to primary schools across England have suggested that the $11 \%$ of the cohort who were bilingual form a subgroup with distinct characteristics. In particular, bilingual children's language difficulties seemed to be more complex and possibly more severe than those of their monolingual peers. It was suggested that these findings might reflect differences in the way that the bilingual children were identified and assessed for speech and language difficulties. Parents of the bilingual children in the original study were interviewed to explore the kind of experiences they had with the identification and assessment process. Differences were found between the bilingual parents and a group of monolingual parents who were also interviewed. Moreover, differences were found between two subgroups of the bilingual parents: those who were 'more informed' and 'less informed' about the process. These differences were found to be related to several other factors, including attitudes to language use within the family and the nature of the parents' relationship with the language unit.

\section{0-692 Francis, Norbert (Northern Arizona U.,} USA; Email: norbert.francis@nau.edu). Bilingualism. writing, and metalinguistic awareness: oral-literate interactions between first and second languages. Applied Psycholinguistics (Cambridge; UK), 20, 4 (1999), 533-61.

This article reports on an investigation of the development of literacy, bilingualism, and metalinguistic awvareness. The particular context of the study (high levels of bilingualism among school-age children) and the particular language contact situation (an indigenous language) offer a vantage point on the interaction between language learning and metalinguistic awareness and take into account the sociolinguistic imbalances which characterise bilingual communities of this type. The participants in the study were speakers of Spanish and Náhuatl from Central Mexico. Assessments of metalinguistic awareness related to different aspects of the children's consciousness of the languages they spoke or understood were compared to a series of assessments of reading comprehension, writing, and oral narrative in both languages. Findings suggest directions for further research along the following lines: metalinguistic awvareness is related to different aspects of literacy development in different ways, the key variables being the degree of decontextualisation and expressive versus receptive language tasks.

\section{0-693 Harklau, Linda (U. of Georgia, USA).}

From the 'good kids' to the 'worst': representations of English language learners across educational settings. TESOL Quarterly (Alexandria, VA, USA), 34, 1 (2000), 35-67.

Based on year-long ethnographic case studies followiing U.S. immigrants in their last year of secondary school and first year in a two-year community college, this article contrasts prevalent institutional images of what it means to be an English language learner in these two educational settings. The article drats on the notion of representation, of archetypal images of learner identity, arguing that representation offers a means of understanding how seemingly self-evident and unchanging identities emerge in a particular social context out of ever-evolving processes of identity (re)creation. The article compares representations of English as a Second 
Language (ESL) student identity in the two educational institutions, and illustrates the manifestation of these representations in class curricula and spoken and written interactions. Prevalent institutional images of ESL student identities were appropriated and recreated by students and educators in one context and resisted by students in another. Contending that representation is an inevitable part of human meaning making and identity formation, the article suggests that images of students and of their backgrounds, experiences and needs not only inform curriculum but also have significant consequences for students' identities and attitudes toward classroom learning.

00-694 Kanno, Yasuko (Keio U. and Teachers Coll., Columbia U., Tachibono, Kugenuma, Fujisowo, Japan; Email: ykanno@sfc.keio.ac.jp). Bilingualism and identity: the stories of Japanese returnees. International Journal of Bilingual Education and Bilingualism (Clevedon, UK), 3, 1 (2000), 1-18.

This study examines the relationship between bilingualism and identity by drawing upon the examples of kikokushijo, the children of Japanese expatriates. Kikokushijo's lives provide a fertile ground in which to explore the interplay between bilingualism and identity. In North America their second language (English) is the majority language, first language (Japanese) the minority; after their return to Japan this situation is reversed. Four kikokushijo's stories of cross-cultural experience over a period of three years were collected as they moved from Canada back to Japan. The results show that the students attributed different symbolic meanings to their two languages: the majority language in each context was seen as the key to participation in society; the minority language, on the other hand, represented their difference from the majority, an enblem of their uniqueness. The different roles that each language plays in various contexts are seen as representing the two conflicting desires of many bilinguals: a desire to be included in society's 'mainstream' and a need to assert their uniqueness. Implications for the education of bilingual students are discussed.

00-695 Klingner, Janette K. (U. of Miami, Florida, USA) and Vaughn, Sharon. The helping behaviours of fifth graders while using collaborative strategic reading during ESL content classes. TESOL Quarterly (Alexandria, VA, USA), 34, 1 (2000), 69-98.

This study investigated the frequency and means by which bilingual students helped each other and their limited English proficient peers in content classes while working in small, heterogeneous groups as they implemented a reading strategy: collaborative strategic reading. Overall, students in groups spent large amounts of time engaged in academic-related strategic discussion and assisted one another in understanding word meanings, getting the main iden, asking and answering questions, and relating what they were learning to previous knowledge. Furthermore, each group provided some explanation in Spanish. Students' scores on English vocabulary tests improved significantly from pre- to post-testing. Results revealed that students' helping behaviours were facilitated by the provision of specific instruction in how and when to help their peers. The authors reconmend this method of strategy training for content area group work.

\section{0-696 Mac Fhlannchadha, Pádraig.}

Codemixing and codeswitching among children in an Irish immersion school. Teanga (Dublin, Ireland), 18 (1999)، 42-63.

This study attempts to explain the phenomenon of codeswitching in an under-researched bilingual context, i.e., that of Irish-English codemixing and codeswitching by sequential bilingual children in an all Irish language immersion school. It examines the extent to which the interlanguage of the informants-26 7-8 year olds-is illustrative of linguistic weakness in the form of mixing, or to what extent they have the ability to codeswitch which involves both linguistic and pragmatic competence, both essential factors in learning a language. The linguistic analysis examines the structural properties of the switches and the kinds of knowledge that the emerging patterns reflect. A description is given of how the switched elements are integrated morphologically and syntactically in relation to the unswitched sections of the discourse. The pragmatic analysis attempts to explore what stylistic functions are evident in the data having taken situational factors (setting, discourse type, participants and topic) into account and to what extent these are indicative of the children's pragmatic competence. Within the pragmatic analysis, the informants' strategic competence as second language (L2) learners is examined and the occurrence of mixing and switching as L1 communication strategies is compared to that of L2 based communication strategies. Finally, factors influencing pedagogical practice are explored.

00-697 Malallah, Seham (Kuwait U., Kuwait; Email: sehammalallah@hotmail.com). English in an Arabic environment: current attitudes to English among Kuwait university students. International Journal of Bilingual Education and Bilingualism (Clevedon, UK), 3, 1 (2000), 19-43.

This paper reports research carried out with Kuwait University undergnduates enrolled in English courses in order to examine students' attitudes and motivations to learning English as a foreign language in a predominantly Arabic and Moslem environment. The research focuses on the inter-relationships between attitude, motivation, anxiety and achievement in the English language. Despite studies which seem to show that Kuwaitis are not in favour of English or of learning the language, the researcher offers three hypotheses: (1) that the undergraduates, in general, have positive attitudes towards learning English, towards the English language and towards native speakers of English; (2) that Kuwait 
society values and regards English highly; and (3) that students' achievement is positively related to their motivation and attitudes toward English and negatively related to their anxiety. In general, these hypotheses were vindicated by the research, which also found that the more a student is exposed to English, and the more they need it either for present studies or for future career, the more positive their attitudes appear towards the language.

00-698 Moore, Leslie C. (U. of California, LA, USA). Language socialisation research and French language education in Africa: a Cameroonian case study. The Canadian Modern Language Review / La Revue canadienne des langues vivantes (Toronto, Ont.), 56, 2 (1999), 329-50.

This article reports on exploratory ethnographic research on language acquisition and use in a village located in the Mandarn Mountains, Cameroon. The study indicates that members of this community share several beliefs and practices related to multilingual communicative competence and its development. In the school attended by children of this village, classroom practices of communication and language socialisation differ significantly from those of the community. Discontinuities between community and classroom practices and their implications for French acquisition by children of this community are discussed. The article concludes with a discussion of how language socialisation research can contribute to our understanding of community/classroom discontinuities and their consequences for classroom French acquisition, and thus to efforts to improve French language pedagogical practice in Africa.

00-699 ó Laoire, Muiris (Inst. of Tech., Tralee, Co. Kerru, Éire; Email: molaoire@tinet.ie). Learning Irish for participation in the Irish language speech community outside the Gaeltacht. Journal of Celtic Language Learning (Paramus, NJ, USA), 5 (2000). 20-33.

Until the early seventies, Irish language pedagogy as part of the state's interventionist role in language revival was seen to constitute a symbiotic strategy for language maintenance, status planning and acquisition planning for the language. The present author questions whether, since 1970, there has been a change in state policy for Irish language pedagogy; whether Irish is now being taught and learned as a second language, with the objective of achieving a societal bilingualism; and to what extent learning Irish in schools at present guarantees rates of reproduction of sequential bilinguals to ensure consolidation and extension of the speech community pobal ua Gaeilge. Pobal na Gacilge, as well as including the territorially defined Gacltachtai (Irish language speech communities), significantly refers to a growing number of networks of users of Irish outside that regional, territorial and linguistic entity. This paper examines the present requirements for accountability in
Irish language pedagogy, (e.g., syllabus, societal bilingualism and state revival policies). The author argues that Irish language pedagogy needs to address realistically the present focus of revival policy programmes, in order to achieve meaningful and purposeful language learning in the classroom.

00-700 Shin, Sarah J. (U. of Maryland, Baltimore County, USA; Email: shin@umbc.edu) and Milroy, Lesley. Bilingual language acquisition by Korean schoolchildren in New York City. Bilingualism: Language and Cognition (Cambridge, UK), 2, 2 (1999), 147-67.

This paper examines the bilingual language development of young Korean-American children in respect of their acquisition of English grammatical morphemes and the different plural marking systems of Korean and English. Two specific issues are addressed: (1) whether first (L1) and second language (L2) learners acquire the grammatical features of a given languige in the same sequence; and (2) whether L2 learners of different L1 backgrounds learn the grammatical features of a given second language in the same sequence. Comparison of the results with those of other morpheme acquisition studies suggests that L1 and L2 learners of English do not acquire English granmatical features in the same sequence. Furthermore, there is evidence that first language influences the course of second language acquisition. Results of an experimental study of plumal marking suggest that the bilingual children in most, but not all, respects follow similar, but delayed patterns of first language acquisition of Korean and successive acquisition of English.

00-701 Smith, Kara A. (U. of Windsor, Ontario, Canada; Emait: ksmith@uwindsor.ca). Gaelic language maintenance typologies and constructs. Journal of Celtic Language Learning (Paramus, NJ. USA), 5 (2000), 34-61.

This paper reports the qualitative results of a 19951997 ethnographic study of 17 Gaelic language users living within English-speaking areas of Canada and Scotland. The participants, who were observed for a period of nine days, kept a written journal in which they recorded their thoughts and feelings about Gaelic, and about their Gaelic worlds and their Gaelic language maintenance within an English community. These records formed two typologies, 'Levels of Gaelic Speech Competence' and 'Gaelic Social Roles'; and two language maintenance constructs, 'Interactive Gaelic Work' and 'Interlinguistic Relations'. The typologies and constructs of these successfill Gaelic language maintenance users internct dynamically to identify other speakers' reference groups and, based on the reference group identified, whether the user would choose to engage in a sustained Gaelic conversational episode with the other speaker. Results identified a 'common sense' ethnographic method of evaluating levels of Gaelic speech ability and Gaelic roles by using the natural terms of the lesser-used language community studied. 
00-702 Stevens, Gillian (U. of Illinois at UrbanaChampaign, USA; Emait. gstevens@uiuc.edu). Age at immigration and second language proficiency among foreign-born adults. Language in Society (Cambridge, UK), 28, 4 (1999), 555-78.

Sociologists typically assume that immigrants' acquisition of English as a Second Language follows the opportunities and motivations to become proficient in English, while many linguists argue that second language acquisition may be governed by maturational constraints, possibly biologically based, that are tied to the age at onset of language learning. This article uses U.S. census data to investigate the relationship between age at onset of second language learning and levels of English language proficiency among foreign-born adults in the United States. The overnrching conclusion is that proficiency in a second language among adults is strongly related to age at immigration. Part of that relationship is attributable to social and demographic considerations tied to age at entry into a new country, and part may be attributable to maturational constraints.

00-703 Toohey, Kelleen, Waterstone, Bonnie and Julé-Lemke, Allyson (Simon Fraser U., Canada). Community of learners, carnival, and participation in a Punjabi Sikh classroom. The Canadian Modern Language Review/La Revue canadienne des langues vivantes (Toronto, Ont.), 56, 3 (2000), 421-36.

This paper examines classroom activities engaged in by more and less experienced speakers of English and discusses how relationships between those speakers are implicated in their speech activities. The pivotal role of social interaction in learning has been well formulated by sociocultural researchers, including Vygotsky (1978) and, more recently, Rogoff (1994). Bakhtin's (1984) notion of carnival also contributes to the present discussion of how social relations in the particular Punjabi Sikh classroom investigated facilitate or constrain the participation of classroom members. Three occasions in the life of this Grade 1 classroom are examined: a common, teacher-directed interaction (Initiation-ResponseEvaluation sequence); an excerpt of children at play; and a playful interaction between an adult and a group of children. This study suggests that a certain type of adult participation may facilitate opportunities for children's participation in conmunity activities and for learning.

\section{Sociolinguistics}

00-704 Chavez, Monika (U. of WisconsinMadison, USA). Teacher and student gender and peer group gender composition in German foreign language classroom discourse: an exploratory study. Journal of Pragmatics (Amsterdam, The Netherlands), 32, 7 (2000), 1019-58.

In recent years, issues of gender have gained greater prominence in second language (L2) research.
However, gender has received little or no attention in the study of classroom discourse, despite the fact that communication in the L 2 often is both the means and the goal of language instruction. This explomtory study draws on gender-related research in first and second language, as well as on student self-reported data (via 201 questionnaire responses from university students of German in the U.S.A.), to outline specific points for further, observational investigations of the effects of student, peer group, and teacher gender.

00-705 Ntlhakana, Pearl (U. of Central England, UK). People's English. English Today (Cambridge,

UK), 16, 2 (2000), 11-17.

This article examines the impact of a new langunge policy on English in education in South Africa. Although a multilingual language policy recognising eleven languages has been in place since 1994, English remains the dominant language in public domains. Under apartheid the medium of education varied according to race and place of residence. English language teaching in black schools was of a comparatively low standard because it was under-funded, understaffed and under-resourced. While these issues are being redressed, there has as yet been little impact on current education trends. Black students tend to apply to new 'black universities' with few of them matriculating for the established 'white universities' because of poor competence in English. It is suggested that improved teaching and access to native varieties of English is leading to the development of a new variety, 'People's English', or Black South African English (BSAE). As the status of BSAE has improved, it has been cited as a threat to white South African English. However, the author concludes that as English language teaching improves and BSAE becomes more widely spoken it will move closer to standard South African English.

00-706 Thibault, Pierrette and Sankoff, Gillian (U. of Montreal, Canada). L'évaluation du français des jeunes Anglo-montréalais par leurs pairs francophones. [Evaluation of young anglophone Montrealers' French by their francophone peers.] The Canadian Modern Language Review/La Revue canadienne des langues vivantes (Toronto, Ont.), 56, 2 (1999), 245-81.

This article analyses the reactions of 116 francophone Montrealers to the recorded speech of English speakers using French. Adapting the classical 'matched guise' approach, where judgements are made on the same voices disguised under different accents, the test was built around stylistic rather than dialectal variation, using reading and conversational segments from the same speakers. The researchers were mainly interested in finding out which linguistic traits of speech triggered the judgements on the speakers' competence and to what extent they met the judges' expectations with regard to their job suitability. It appears that practically all the 14 linguistic variables considered were strongly 